\title{
O CONCEITO DE PULSÃO NA PSICANÁLISE FREUDIANA: CONSIDERAÇÕES A PARTIR DA FILOSOFIA DE MARTIN HEIDEGGER
}

\author{
Jilvania de Jesus Barbosa ${ }^{1}$ \\ Caroline Vasconcelos Ribeiro ${ }^{2}$
}

RESUMO: Na obra Seminários de Zollikon Heidegger afirma que Freud, ao conceber o psiquismo como um aparelho mobilizado por um jogo de forças pulsionais, alinha seu saber com o perfil explicativo das ciências da natureza. Ao destinar uma semântica fisicalista para pensar os fenômenos psíquicos, a exemplo do conceito de pulsão, a psicanálise freudiana estaria ancorada em procedimentos afinados aos das ciências naturais. Heidegger questiona o entendimento dos fenômenos humanos a partir deste tipo de semântica e indica que a sua compreensão de homem enquanto Dasein (ser aí) se opõe a este tipo de conceituação. $O$ filósofo assevera que, ao postular a existência de uma força mobilizando a máquina psíquica, Freud estaria destinando ao homem categorias que são estrangeiras aos seus modos de existir. No texto Ansiedade e Vida Pulsional, Freud se refere à teoria das pulsões como sua mitologia e à pulsão 
como uma entidade mítica. Com este artigo, pretendemos colocar em discussão o conceito freudiano de pulsão, tendo em vista a posição de Heidegger quanto ao seu caráter científico-natural e o argumento de Freud que indica tratarse de um conceito obscuro, de uma entidade mítica.

PALAVRAS-CHAVE: Dasein; Freud; Heidegger; Pulsão.

ABSTRACT: In the work "Zollikon Seminars" Heidegger affirm that Freud, when designing the psyche as a unit mobilized by a set of instinctual forces, aligns their knowledge with the explanatory profile of the natural sciences. By destining a physicalist semantics to think about psychic phenomena, such as the concept of drive, Freudian's psychoanalysis would be anchored in procedures according to the natural sciences. Heidegger questions the understanding of human phenomena from this type of semantics and indicates that his understanding of man as Dasein (being there) is opposed to this type of concept. The philosopher asserts that, by postulating the existence of a force mobilizing the psychic machine, Freud would be destining to the man categories that are foreign to their way of being. In the text "Anxiety and Instinctual Life", Freud refers to the theory of drives (Trieb) as their mythology and drive as a mythical entity. With this article, we intend to put in discussion the Freudian concept of drive (Trieb), 
REVISTA IDEAÇÃO, EDIÇÃO ESPECIAL 2018

considering the position of Heidegger as to be scientific and natural character, and the Freud's argument indicating that this is an obscure concept, of a mythical entity.

KEYWORDS: Dasein; Freud; Heidegger; Drive (Trieb). 
$\mathrm{O}$ artigo em questão tem a tarefa de explicitar a veemente crítica de Heidegger dirigida à Psicanálise freudiana. Nesta conjuntura, traremos o constructo pulsão como um dos conceitos metapsicológicos alvo das considerações deste filósofo na obra Seminários de Zollikon. Estes seminários foram decorrentes da iniciativa de Medard Boss, psiquiatra suíço que solicitou a Heidegger uma ajuda para pensar filosoficamente problemas do campo da psicoterapia. A partir deste convite, o filósofo alemão se dispôs a ministrar em Zollikon seminários regulares, durante dez anos (19591969), para um grupo de estudantes de medicina e psiquiatras. Estes seminários foram registrados e, posteriormente, organizados e editados por Medard Boss na obra supracitada. Nessa obra encontramos críticas a respeito do tratamento que as ciências do psiquismo, em especial a psicanálise de Freud, destinaram ao homem.

Do ponto de vista heideggeriano, muitas teorias psiquiátricas e a própria teoria freudiana ergueram-se pagando tributo aos imperativos metodológicos das ciências naturais. Sendo assim, não conseguiriam abarcar o existir humano e seus modos de ser, posto que transferem a objetividade das ciências da natureza para fenômenos exclusivamente humanos. Heidegger (2001) critica a forte presença de um fisicalismo na linguagem freudiana, constatável, por exemplo, na formulação de termos como aparelho psíquico, força pulsional, princípio de constância. 
O filósofo considera que a ciência que visa o estudo dos fenômenos humanos necessita ser pensada e orientada segundo bases diferentes das que constituem as ciências da natureza.

Para o pensador em questão é necessário distinguir a maneira como a ciência humana deve compreender o homem daquela que explica os fenômenos não-humanos. ${ }^{3}$ $\mathrm{O}$ que está em questão é a linguagem que possibilita o acesso ao fenômeno. Nessa perspectiva, para falar do humano torna-se necessário se ancorar em uma semântica que não provenha da física, da química ou de qualquer outra ciência natural. Freud pensa o psiquismo a partir de um intenso jogo de forças pulsionais e compara-o a um aparelho, cujo funcionamento se dá de modo semelhante a um telescópio ou qualquer outro aparelho óptico. Ao questionar o entendimento dos fenômenos humanos a partir deste tipo de semântica, Heidegger aponta que a sua compreensão de homem enquanto Dasein (Ser-aí) ${ }^{4}$ se opõe ao modo de conceituação que visa objetificá-lo, ou seja, que visa dar-lhe um tratamento afinado com o que é destinado aos entes naturais. O que implica dizer que seu modo de pensar se opõe à visão do psiquismo como um aparelho movido por forças pulsionais antagônicas.

Já que o conceito de pulsão é o alvo de nosso artigo e da crítica de Heidegger a Freud, precisamos cumprir a etapa de clarificação sobre o sentido e a função deste na teoria 
freudiana. Para tanto, temos que tecer uma breve explanação a respeito da metapsicologia, componente da teoria freudiana onde o referido conceito se aloca. Posteriormente, explanaremos sobre a natureza da crítica de Heidegger a este conceito.

De acordo com o pesquisador Leopoldo Fulgencio (2003a, p. 129), no texto As especulações metapsicológicas de Freud, a teoria freudiana é composta por dois aspectos. Um aspecto empírico - a sua psicologia dos fatos clínicos - e outro especulativo, a metapsicologia. ${ }^{5}$ Este último é considerado por Freud como uma superestrutura teóricoespeculativa, cujos conceitos são passíveis de serem substituídos por outros mais frutíferos. Nesta parte da psicanálise se encontram conceitos que estão para além da observação, como o de pulsão, inconsciente, aparelho psíquico e recalque, por exemplo.

Freud se serve de conceitos de natureza especulativa, ou seja, metapsicológica, sempre que não consegue apreender empiricamente um dado fenômeno. Com este tipo de teorização o pai da psicanálise espera obter explicações que completem as lacunas dos fenômenos observáveis. Ao postular que nosso psiquismo funciona como um aparelho, com uma instância inconsciente e movido por forças denominadas pulsões, Freud não pretendeu apresentar uma prova empírica desta força e muito menos a localidade anatômica da máquina psíquica e 
de seu inconsciente. Quer dizer: esse tipo de conceito não é postulado com o intuito de provar-lhe a realidade empírica, mas com o fito de utilizá-lo para ordenar fatos, torná-los explicáveis.

Fulgencio (2003a) indica que o uso de especulações para ordenar e explicar fenômenos empíricos é algo que segue o molde procedimental da ciência da natureza típica do século XIX, da qual Kant seria o patrono. De modo sumário, cabe destacar que tal programa pressupõe o uso de ideias abstratas com o objetivo de aclarar os fenômenos empíricos. Kant, na obra Princípios metafísicos da ciência da natureza (1990), afirma que uma "teoria racional da natureza só merece, pois, o nome de ciência natural se as leis da natureza, que lhe subjazem, forem conhecidas a priori e não forem simples leis da experiência" (KANT, 1990, p. 14). Segundo Fulgencio (2003a, p.148-149), isto implica dizer que a ciência natural também caminha através de conceitos puros criados pela razão, ideias que não encontram suporte na experiência e que, portanto, não podem ser confundidas com dados empíricos.

Para Kant, a verdadeira ciência natural pressupõe uma metafísica da natureza. Tal metafísica deve conter “(...) sempre puros princípios, que não são empíricos (é por isso que leva o nome de metafísica)" (KANT, 1990, p.15). Na perspectiva instituída por Kant a complementação de lacunas pode ser auxiliada por certas especulações postas 
pela razão. Almejamos mostrar que esse recurso acontece na psicanálise de Freud e que seus conceitos especulativos são exemplos desse modelo.

No projeto kantiano para as ciências naturais o uso de conceitos relacionados à metafísica da natureza é considerado um recurso lícito para formular o quadro teórico da ciência empírica. Fulgencio (2008) afirma que o uso de especulação aponta para o reconhecimento do limite do conhecimento possível de ser atingido apenas pela observação e especifica que há um tipo de saber que pode ser oferecido por conceitos formulados especulativamente. No caso de Freud, o comentador nos indica que esse era o recurso utilizado para suprir as lacunas encontradas diante dos fatos clínicos. Por isso, o pai da psicanálise se serviu de conceitos de natureza auxiliar, que funcionavam apenas como convenções e que jamais deveriam ser confundidos com os que possuem referencial empírico.

O exame da metapsicologia de Freud dá pistas de que seus conceitos têm caráter convencional, assim como os conceitos abstratos utilizados pelas ciências da natureza para ordenar dados empíricos. Posto que indicamos, ainda que em traços largos, a natureza da teoria metapsicológica, cabe agora descrever de que modo Freud concebe o postulado pulsão, alocado no bojo desta teoria. ${ }^{6}$ 


\section{O CONCEITO DE PULSÃO (TRIEB) NA METAPSICOLOGIA FREUDIANA.}

No artigo A pulsão e seus destinos, Freud indica que "a pulsão tem origem no corpo, considerada como um estímulo para o psíquico, algo que, de fora, exige um trabalho do aparelho psíquico levando-o a funcionar" (FREUD, 1996b, p.129). Sendo assim, na condição de força que atua sobre o aparato psíquico, a pulsão é o que lhe dá mobilidade. Possui duas características essenciais: "a sua origem em fontes de estimulação dentro do organismo e seu aparecimento como força constante" (FREUD, 1996b, p.129). A pulsão não tem origem no psíquico, é importante esclarecer que sua gênese é somática, isto é, a fonte da pulsão é o corpo. Neste sentido, Freud afirma que se trata de:

(...) um conceito situado na fronteira entre o mental e o somático, como representante psíquico dos estímulos que se originam dentro do organismo e alcançam a mente, como uma medida da exigência feita à mente no sentido de trabalhar em consequência de sua ligação com o corpo (FREUD, 1996b, p.129).

Para Freud a pulsão consiste num componente, oriundo de uma estimulação do organismo, que penetra no 
campo psíquico, ou seja, "é uma espécie de delegação enviada pelo somático ao psiquismo" (LAPLANCHE E PONTALIS, 2001, p. 395). O corpo é a fonte de estimulação constante para a pulsão, a qual penetra como exigência de trabalho no aparelho psíquico. Como adverte Garcia-Roza (1995, p. 82), "a pulsão pode ser considerada um estímulo para o psíquico - der Trieb sei ein Reinz für das Psychische estímulo para o psíquico e não estímulo psíquico.” Mas uma questão se impõe: se a pulsão (Trieb) nasce de uma excitação das zonas corporais, como essa força entra no aparelho psíquico? De acordo com Hans (1996), no Dicionário comentado do alemão de Freud:

O Trieb brotará no indivíduo como fenômeno somático-energético, sendo descrito por Freud como processo fisiológico (envolvendo termos como neurônios, nervos, fontes pulsionais situadas nas glândulas etc.) e como processo energéticoeconômico (acúmulo de energia, descarga etc.). De outro lado, o Trieb aparecerá para o indivíduo, isto é, será percebido como fenômeno psíquico (ideia, vontade, dor, medo, sensações) e irá impeli-lo a praticar certas ações. Assim, o Trieb brota como fenômeno físico e orgânico e atinge a mente como fenômeno psíquico (HANS, 1996, p. 351). 
Como aponta o autor supracitado, a pulsão surgirá no corpo, inicialmente, como um fenômeno orgânico, envolvendo um processo energético e será "percebida" apenas como fenômeno psíquico quando se fizer presente no psiquismo. Garcia-Roza (1995, p. 242) esclarece que a pulsão só pode se fazer presente no psiquismo através de dois delegados: a representação (Vorstellung) e do afeto (Affekt). Segundo este comentador, o afeto é entendido por Freud como a expressão qualitativa do quantum de energia pulsional e a representação (Vorstellung) é concebida como representante ideativo. Garcia-Roza segue explicando que, apesar de $\mathrm{o}$ afeto se ligar originalmente a uma representação, “(...) a ligação entre eles não é necessária podendo o afeto se deslocar de uma representação para outra sem ficar preso a uma delas" (GARCIA-ROZA, 1995, p. 120).

Apesar de o afeto e da representação estarem inicialmente ligados, eles podem se dissociar. Desligados um do outro no mundo anímico, um afeto pode se ligar a outro representante psíquico. Sobre o desligamento da representação e afeto Freud (2006a, p. 29) afirma: "uma vez que a representação ideacional foi tirada de cena, a moção, para poder veicular-se, foi obrigada a estabelecer uma nova conexão com outra representação mental, que agora passa a representá-la." À medida que o afeto se desprende da representação, este pode encontrar expressão aliando-se a 
outra representação. Aqui cabe perguntar: por que a representação se desprende do afeto? A resposta desta questão está implícita no conceito de recalque, termo cunhado por Freud para designar a defesa do psiquismo contra conteúdos que trariam desprazer.

Na obra $O$ recalque (2006b, p.177) o pai da psicanálise diz que "uma moção pulsional é recalcada quando ao atingir sua meta produz desprazer ao invés de prazer”. Neste caso, a pulsão é recalcada, ou seja, o conteúdo ameaçador é retirado da luz da consciência. De modo geral, vale destacar que o recalque não impede o representante pulsional de continuar existindo no inconsciente, de continuar a fazer novas ligações.

Além dos dois componentes que representam a pulsão no psíquico, Freud (1996b, 127) faz referência a quatro termos ligados ao conceito, a saber: pressão, finalidade, objeto e fonte. De modo sucinto, convém explicitar que por pressão [Drang] de uma pulsão compreende-se seu fator motor, a quantidade de força ou a medida de exigência de trabalho que ela representa. A finalidade [Ziel] da pulsão, diz Freud em seu artigo metapsicológico sobre o tema, é sempre a satisfação obtida através da estimulação da fonte. O objeto [Objekt] é o caminho através do qual a pulsão é capaz de atingir sua finalidade. Por fonte [Quelle] Freud (1996b, p. 128) compreende um processo que se origina em alguma parte do corpo e que se faz presente no psíquico 
através da presentação da pulsão (Triebrepräsentanz). Porém, o pai da psicanálise diz não saber ao certo se este processo tem natureza química ou se corresponde, por exemplo, a forças mecânicas.

Embora Freud tenha postulado o conceito de pulsão levando em consideração suas observações clínicas, o mesmo considera que "as pulsões são o mais importante e também o mais obscuro objeto da investigação psicológica" (2006b, p. 158). Mesmo considerado obscuro, trata-se de um conceito necessário. No artigo A pulsão e seus destinos o psicanalista (1996b, p. 123) declara que o uso de material especulativo, ou seja, de convenções teóricas é indispensável para o fazer científico. No artigo em comento, Freud afirma que não se pode fazer ciência só com observação de fenômenos ou com conceitos claros e bem definidos. Sendo assim, o cientista é forçado a se servir de constructos que são obscuros e abstratos, mas que têm valor para explicar os fenômenos. Segue argumentando que, na física, o conceito que evoluiu sob estatuto de uma ficção teórica é o conceito de força. Em sua ciência, diz Freud, há um conceito equivalente: pulsão. Trata-se de um conceito obscuro, mas indispensável à sua teoria. No começo deste texto sobre os destinos das pulsões, o pai da psicanálise esclarece a natureza da tarefa científica e defende o uso de convenções como um a prática de ciência, inclusive da mais "dura" delas: a física. Diz o autor: 
O CONCEITO DE PULSÃO NA PSICANALISE FREUDIANA...

O verdadeiro início da atividade científica consiste antes na descrição dos fenômenos, passando então a seu agrupamento, sua classificação e sua correlação. Mesmo na fase de descrição não é possível evitar que se apliquem certas ideias abstratas ao material manipulado, ideias provenientes daqui e dali, mas por certo não apenas das novas observações. Tais ideias - que depois se tornarão os conceitos básicos da ciência - são ainda mais indispensáveis à medida que o material se torna mais elaborado. [...] Assim, rigorosamente falando, elas são da natureza das convenções - embora tudo dependa de não serem arbitrariamente escolhidas, mas determinadas por terem relações significativas com o material empírico, relações que parecemos sentir antes de podermos reconhecê-las e determiná-las claramente. [...] O avanço do conhecimento, contudo, não tolera qualquer rigidez, inclusive em se tratando de definições. A física proporciona excelente ilustração da forma pela qual mesmo 'conceitos básicos', que tenham sido estabelecidos sob a forma de definições, estão sendo constantemente alterados em seu conteúdo (FREUD, 1996b, p.123).

Freud diz que pulsão é ideia abstrata, que não é segura, é imprecisa, mas fundamental. A pulsão equivale ao conceito de força motriz. A ciência que instituiu o conceito de força foi a física. Para tal ciência este conceito também 
corresponde a uma ideia abstrata, porém frutífera. A obscuridade do conceito de pulsão é mais uma vez assumida quando Freud trata o constructo como algo relativo a uma entidade mítica. No texto Ansiedade e vida pulsional, de 1933, Freud afirma:

A teoria das pulsões é, por assim dizer, nossa mitologia. As pulsões são entidades míticas, magníficas em sua imprecisão. Em nosso trabalho, não podemos desprezá-lo, nem por um só momento, de vez que nunca estamos seguros de os estarmos vendo claramente (FREUD, 1996a, p.98).

Somos tentados a pensar que, por se tratar de uma entidade mítica, o conceito de pulsão não poderia, como argumenta Heidegger (2001, p.192), estar associado a um cientificismo natural. Parece ser um conceito que, ao contrário do que Heidegger pressupõe, retira da psicanálise as condições de ser uma ciência da natureza. Como imprecisão, mitologia e obscuridade - qualidades destinadas por Freud ao conceito de pulsão - podem estar associadas a uma identidade científico-natural? Veremos, a seguir, que Heidegger e alguns pesquisadores da área da Filosofia da Psicanálise, como Zeljko Loparic e Leopoldo Fulgencio, indicarão que se trata de um conceito que carrega consigo heranças das ciências da natureza. Depois 
de explicitarmos a natureza das análises destes autores, nos perguntaremos se, de fato, é possível detectar uma herança científico-natural no conceito de pulsão. Julgamos conveniente explanar previamente sobre a maneira como Heidegger o aborda e sobre o conceito de homem que ele se serve para contrapor-se à Freud.

\section{A CRÍTICA HEIDEGGERIANA AO CONCEITO DE PULSÃO (TRIEB) E 0 HOMEM ENQUANTO DASEIN.}

Como indicamos acima, Heidegger, na obra Seminários de Zollikon, traça uma série de questionamentos acerca da psicanálise freudiana. Segundo o filósofo, Freud formula conceitos inspirando-se nas ciências da natureza. Um exemplo disso pode ser percebido na tentativa freudiana de explicar as urgências humanas com o conceito de pulsão. Sobre isso Heidegger pondera:

Para se reconduzir o querer, o desejar, tender e ansiar a 'pulsões' então deve-se sempre, em primeiro lugar, contra-argumentar: será que em toda construção freudiana da teoria da libido o homem está mesmo ai? Pulsão é sempre uma tentativa de explicação, mas é preciso observar, em primeiro lugar, o que é mesmo o fenômeno que se quer 
explicar e como ele é. Tenta-se sempre explicar por pulsões algo que, pra começar, nem se viu. As tentativas de explicação dos fenômenos humanos a partir de pulsões têm o caráter metódico de uma ciência, cuja matéria não é o homem, mas sim a mecânica. Por isso, é fundamentalmente discutível se um método tão determinado por uma objetividade não-humana pode mesmo ser apropriado para afirmar o que quer que seja sobre o homem qua homem (HEIDEGGER, 2001, p.192).

No trecho transcrito acima, Heidegger questiona a possibilidade de se alcançar o homem a partir da pressuposição de que estamos submetidos psiquicamente a um o jogo de forças que se polarizam. Para o filósofo este tipo de explicabilidade corresponde às coisas alheias ao existir humano. Ao abordar fenômenos genuinamente humanos através de conceitos como pulsão, princípio de constância, dentre outros, Freud teria afinado seu saber com as ciências da natureza e, por conseguinte, coisificado o homem, destinando-lhe pretensões de objetividade típicas destas ciências. Para Heidegger, esse tipo de tratamento não alcança o homem em sua completude porque observa-o enquanto algo simplesmente presente na natureza.

Surge a questão: seria possível atingir, desta forma, o ser do homem? Para Heidegger, dentro desse projeto 
O CONCEITO DE PULSÃO NA PSICANALISE FREUDIANA...

científico-natural só podemos vê-lo como ente natural, quer dizer, “(...) temos a pretensão de determinar o ser do homem por meio de um método que absolutamente não foi projetado em relação à sua essência peculiar" (HEIDEGGER, 2001, p.57).

Mas, como Heidegger pensa o homem? Em que medida o seu modo de abordar o ser humano se distancia do freudiano? Como indicamos acima, Heidegger pensa o homem enquanto Dasein, ser-aí. Segundo Inwood (2002, p. 29), a palavra Dasein já existia na etimologia alemã corrente, significando aquilo que está "presente", "disponível", "existir". No século XVII, Dasein teve o sentido de "presença" (Dass-sein). No século XVIII os filósofos passaram a usá-la como derivada do latim Existenz ("a existência de Deus", por exemplo) e os poetas, no sentido de "vida". Em Carta sobre o humanismo, Heidegger (2009, p. 43) nos indica que o termo Dasein, no século XVIII, era usado para designar um objeto, pretendia exprimir o conceito metafísico da realidade do real.

O filósofo da floresta negra dá uma conotação diferente a esta palavra, passando a usá-la exclusivamente para nomear o ente humano. Ser-aí (Dasein) nomeia o modo de relação do homem com o ser. Esta relação é marcada pela abertura da compreensão de ser. Contudo, compreensão não equivale a conhecimento, posto que o existir humano não se encontra fundamentado na 
representação de objetos, mas numa compreensão préteórica que guia o encontro cotidiano com os entes. Sendo assim, compreender (verstehen) é estar aberto para o campo de sentidos abertos no jogo da lida cotidiana com os entes que veem ao encontro do Dasein no modo da ocupação, da manualidade.

Inwood (2002, p. 17) indica que Heidegger, depois de Ser e Tempo (2004), escreveu algumas vezes ver-stehen, enfatizando que compreender algo é ficar de pé, ou fazê-lo ficar, no aberto. Assim entendemos que a compreensão se dá devido à abertura do Dasein para o campo de doação de sentidos. Como dissemos, tais sentidos, de início e na maioria das vezes, abrem-se para o Dasein no cotidiano, na lida e, originariamente, não se relacionam com a consciência e a racionalidade. Heidegger propõe uma maneira inteiramente nova para falar do humano e o termo Dasein cumpre o papel de evitar as categorias tradicionalmente utilizadas para nomear o homem: sujeito, pessoa, consciência, animal racional.

Na obra Que é metafísica? Heidegger (1991) afirma que só o homem existe, pois existir, para o filósofo, significa estar aberto para o ser, para o campo de doação de sentidos revelados pelo ser. Safransky (2000, p. 190) fala sobre a necessidade de diferenciar o ente humano dos demais entes que estão no mundo, ao colocar que: 
O CONCEITO DE PULSÃO NA PSICANALISE FREUDIANA...

Diferentemente do resto do ente, o ser humano tem uma relação com o seu próprio ser. A isso Heidegger chama existência (Existenz). (...) Dasein ou existência significam pois: nós não apenas somos, mas percebemos que somos. E nunca estamos acabados, como algo presente, não podemos rodear a nós mesmos, mas em todos os pontos estamos abertos para um futuro (SAFRANSKY, 2000, p. 190).

De acordo com a perspectiva anunciada por Safransky, o Dasein existe enquanto abertura para um campo de sentido que permite aos entes virem ao seu encontro. É justamente nesta abertura que se dá a compreensão do ser em sua relação com os entes que vêm ao encontro do Dasein. O mundo, nessa perspectiva, é o horizonte de sentidos para tais encontros que se dão, de início e na maioria das vezes, na cotidianidade mediana. Por isso, o mundo mais próximo do Dasein é denominado por Heidegger de mundo circundante (da lida, do cotidiano).

É importante esclarecer que mundo, para Heidegger, não é um receptáculo de objetos disponíveis para a apreensão por parte de um sujeito. Ao invés, "mundo é um caráter do próprio Dasein" (HEIDEGGER, 2004, p. 105). O Dasein só é sendo no mundo. Não podemos, então, entender a relação de Dasein e mundo como se um estivesse 
sobreposto ao outro ou como entendemos a presença de um papel dentro da gaveta. Não somos no mundo como as outras coisas são, por isso, Heidegger utiliza a expressão serno-mundo para falar da relação do Dasein com o mundo. Ser-no-mundo é "um ente que funda todos os seus comportamentos em relação aos entes em geral em um comportamento originário em relação ao mundo" (CASANOVA, 2010, p. 92).

Ao pensar os modos de ser do ente que nós mesmos somos, Heidegger se insurgirá contra a tentativa de capturálo como um ente simplesmente presente, como algo simplesmente dado. Desse modo, afirma que (2001, p.33) “o homem não é de forma alguma e, em nenhuma circunstância, algo possível de objetificação". O filósofo nos lembra que quando tentamos compreender a existência humana com linguagem objetivadora o humano nos escapa. Nessa perspectiva, a linguagem inspirada nas ciências da natureza, cativa à teoria metapsicológica freudiana, principalmente ao conceito de pulsão, não seria adequada para falar do homem enquanto Dasein. O filósofo questiona se é possível alcançar o existir humano de modo genuíno, através de uma abordagem que segue este modelo.

Mas, convém problematizar. Seria lícito pensar que a doutrina das pulsões está ancorada nos pressupostos das ciências duras? Afinal, como vimos, o próprio Freud a considera mitológica. O pai da psicanálise diz: "a doutrina 
das pulsões é, por assim dizer, nossa mitologia" (FREUD, 1996a, p. 98). Não caberia supor que um conceito de ordem mítica levaria a teoria de Freud a uma imprecisão, e a ciência não trabalha com mitos, mas com experimentos, observações. Mitologia é algo impreciso, relativo a uma especulação. Então, convém perguntar se tem fundamento a assertiva de Heidegger que defende que a psicanálise é uma ciência natural e que o conceito de pulsão padece de uma objetividade não-humana. Como uma especulação, uma convenção, pode ser algo que atesta à psicanálise uma identidade científico-natural? Será que o fato de a pulsão ser assumida por Freud como uma convenção impugna a cientificidade natural da psicanálise ou a reafirma?

Queremos defender a tese de que Freud não advoga o uso de convenções por acaso. Para tanto, nos embasaremos em escritos de pesquisadores da área de Filosofia da Psicanálise que dão indícios de que Freud sofreu fortes influências do programa das ciências naturais de seu tempo. Fulgencio (2003a), alerta que:

As proposições teóricas ou conceitos especulativos concebidos como construções auxiliares para realizar pesquisas não são uma inovação de Freud. Ao contrário, bem antes dele, filósofos, cientistas e epistemólogos já haviam analisado esse tipo de método de pesquisa, considerando-o não apenas 
aplicável, mas necessário às ciências naturais (FULGENCIO, 2003a, p.146).

$\mathrm{O}$ pesquisador supracitado alega que Freud concebe a pesquisa científica de modo correspondente àquele já estabelecido em sua época. Este modelo é o das ciências naturais, consagrado no início do século XX. Muito antes de Freud, as convenções já eram utilizadas como complemento para formulações teóricas em muitas ciências. Conceitos como o de força e de átomo podem ser declarados como uma convenção, visto que não possuem realidade empírica. Quer dizer: até mesmo ciências duras como a física e a química se servem de construtos abstratos e, por que não dizer, obscuros como as pulsões freudianas.

Conforme Assoun (1983), na obra Introdução à epistemologia freudiana, Freud encontrou no pensamento do físico e epistemólogo Ernest Mach os fundamentos necessários para embasar sua teoria. Este físico vienense defendeu claramente o uso de representações auxiliares, desde que as mesmas fossem frutíferas para explicar relações observáveis. Fulgencio (2008, p. 143) explora a argumentação de Mach a respeito das convenções e explicita que, para o físico, “essas representações ou conceitos são meras abstrações, úteis ao objetivo procurado, mas que devem ser abandonadas tão logo o desenvolvimento da ciência torne possível a representação direta dos fenômenos 
e suas relações" (FULGENCIO, 2008, p. 143). Mach caracteriza tais representações como representaçõesfantasia, ou seja, como um tipo de bruxaria científica inconveniente, mas necessária. Por isso, Fulgencio comenta que, na perspectiva machiana, “(...) alguns princípios fundamentais que guiaram e guiam a física não são nada mais do que um tipo de mitologia" (FULGENCIO, 2008, p.143). Freud também faz menção a uma espécie de feitiço, bruxaria, ao tratar da teoria pulsional. Segundo ele:

Se nos perguntarem por quais métodos e meios esse resultado [domínio das pulsões] é alcançado, não será fácil uma resposta. Podemos apenas dizer: 'So muss denn doch die Hexedran!' ['Temos de chamar a Feiticeira em nosso auxílio!'] - a Metapsicologia da Feiticeira. Sem especulação e teorização metapsicológica - quase disse 'fantasiar' - não daremos outro passo à frente (FREUD, 1996c, p. 238).

$\mathrm{O}$ recurso à feiticeira deve ser entendido como uma maneira de ir além da observação, tal como fazem, por exemplo, a física e a química. Os conceitos e modelos especulativos de Freud são, assim como as representaçõesfantasia de Mach, superestruturas especulativas que possuem utilidade heurística. ${ }^{7}$ Estes conceitos, portanto, podem ajudar nas pesquisas, desde que não seja esquecido 
que se trata de ficções. Mach, ao analisar a história da ciência natural mais emblemática, a física, nos apontou que esta se apoiou em conceitos que, por serem especulativos, atuam como uma espécie de mitologia. Nessa perspectiva, a física aristotélica, com a consideração dos quatro elementos que comporiam a natureza, e a física newtoniana, com a suposição de que existem forças que impulsionam a natureza, se serviriam de uma mitologia da natureza.

\section{CONSIDERAÇ̃ES FINAIS}

Vimos que Heidegger considera perigoso tratar das urgências humanas usando um conceito que equivale a uma força que impõe trabalho ao psiquismo, por isso enuncia que o conceito de pulsão padece de uma objetividade nãohumana. Para o filósofo em comento, a influência das ciências da natureza na formulação deste constructo torna suspeita a sua capacidade de alcançar o homem enquanto homem.

Em suas críticas à metapsicologia, Heidegger a denunciou como um tipo de instrumento teórico que estaria em desacordo com a natureza dos fenômenos psíquicos, posto que o homem não pode ser abordado por um método tributário das ciências que pensam os entes naturais. Heidegger destaca a filosofia de inspiração 
kantiana e o modelo científico-natural de pesquisa como elementos constitutivos do solo sobre o qual se ergueu e consolidou a metapsicologia de Freud. O filósofo afirma, precisamente, o seguinte: "A metapsicologia de Freud é a transferência da filosofia neokantiana para o homem. De um lado ele tem as ciências naturais e de outro a teoria kantiana da objetividade" (HEIDEGGER, 2001, p. 222) ${ }^{8}$.

A presença da epistemologia machiana nas formulações teóricas de Freud e a influência de Kant no pensamento deste físico vienense são destacadas por Assoun. Em conformidade com este comentador de Freud, através dos ensinamentos de Mach “(...) se propaga uma corrente de pensamento da qual Viena é o centro, em consequência de sua contribuição e ideias propagadas, Viena lhe prestará uma homenagem solene construindo-lhe um monumento" (ASSOUN, 1983, p. 96-97). Ao advogar pela afinidade de Freud com a corrente de pensamento machiana Assoun afirma:

Que Freud faça parte dessa corrente é o que prova pelo menos um episódio pouco conhecido: em 1911, Mach participou da redação de um manifesto em favor da criação de uma sociedade para a difusão da filosofia positivista. Podemos suspeitar que, através desse projeto, reúnem-se, como que em torno de uma bandeira, todas essas correntes. E pode ser 
percebido, entre os signatários, o nome de Freud (ASSOUN, 1983, p. 97).

Além de signatário de uma corrente cientificista cujo manifesto foi redigido pelo eminente físico E. Mach, Freud se serviu de muitas de suas ideias. Assoun adverte que, ao fazer a leitura de Conhecimento e erro, de Ernst Mach, o leitor familiarizado com os textos freudianos pode correr o risco de ser “(...) vítima de um verdadeiro efeito de paramnésia” (ASSOUN, 1983, p. 87). Ainda segundo este comentador, o capital epistemológico da psicanálise tem sua fonte na concepção machiana de ciência, o que lhe faculta identificar certo "isomorfismo entre o texto de Mach e o de Freud" (ASSOUN, 1983, p. 87) ${ }^{9}$.

O uso de um conceito obscuro e de "natureza mítica" como o de pulsão não equivale a uma insurgência contra os imperativos das ciências naturais, mas a uma opção metodológica calcada em seus pressupostos. $\mathrm{O}$ recurso a convenções, a construções auxiliares como os conceitos de inconsciente, pulsão e aparelho psíquico, não equivale a um rompimento com a lógica das ciências da natureza. Ao contrário, equivale a uma tentativa de alocar o saber psicanalítico no elenco destas. Por isso, em várias passagens de seus textos Freud não hesita em reafirmar sua posição: 
O CONCEITO DE PULSÃO NA PSICANALISE FREUDIANA...

Enquanto a psicologia da consciência nunca foi além das seqüências rompidas que eram obviamente dependentes de algo mais, a outra visão, que sustenta que o psíquico é inconsciente em si mesmo, capacitou a Psicologia a assumir seu lugar entre as ciências naturais como uma ciência (FREUD, 1996d, p.170).

Ressaltamos que esta passagem foi retirada de Esboço de Psicanálise, obra tardia de Freud. Cumpre notar que, mesmo tardiamente, depois de ter se desvencilhado das pretensões da neurologia - típicas do início de sua careira Freud continuou afirmando que a sua teoria assumiu um lugar entres as ciências naturais. Em outra passagem, no texto intitulado Algumas lições elementares de psicanálise, ele destaca que a sua Psicologia profunda é uma ciência natural, e se pergunta: “o que mais pode ser?" (FREUD, 1996e, p. 298).

O modelo de psiquismo que Freud postula é análogo a um aparelho, cujos sistemas são interligados. $O$ fluxo de conteúdos no psíquico só pode ser mobilizado através de uma força motriz que lhe é constante: a pulsão. A suposição de forças (pulsões) a atuar no interior do psiquismo entendido como um aparelho - se distancia do modo de abordar o Dasein e reforça a tese heideggeriana de que Freud reduziu o ser humano a um jogo de forças que 
funciona a partir de princípios mecânicos. Por isso, Heidegger, nos Seminários de Zollikon, faz o seguinte alerta aos participantes: “(...) devemos atentar que se trata sempre do existir e não do funcionar de algo. Quando só se visa este último, não se ajuda o Dasen" (HEIDEGGER, 2001, p.180).

Para Safatle (2008), na obra A filosofia após Freud, o modo de abordagem que Freud utiliza descende de uma escolha epistemológica que ele nunca abandonou. Segundo o autor citado: "Qualquer investigação sobre a natureza da mente e da consciência que possa advir do campo psicanalítico tem que levar em conta esse naturalismo psicológico estrito, com o qual Freud jamais rompeu" (SAFATLE, 2008, p. 255).

À luz de Heidegger podemos dizer que este naturalismo objetifica o humano com categorias que devem ser destinadas a entes que não têm o seu modo de ser. $\mathrm{O}$ projeto heideggeriano vai de encontro com a ideia de homem propagada pela psicanálise, posto que Freud visa destinar ao homem um tratamento objetivo e em consonância com as ciências naturais de seu tempo. Para Heidegger (2001) o ente humano, de forma alguma, pode ser acessado tal qual um objeto qualquer, uma vez que o Dasein não é passível de objetificação. Como vimos, o filósofo nos alerta que: 
O CONCEITO DE PULSÃO NA PSICANALISE FREUDIANA...

A ciência natural só pode observar o homem como algo simplesmente presente na natureza. Surge a questão: seria possível atingir desta forma o serhomem? Dentro deste projeto científico-natural só podemos vê-lo como ente natural, quer dizer, temos a pretensão de determinar o ser humano por meio de um método que absolutamente não foi projetado em relação a sua essência peculiar (HEIDEGGER, 2001, p. 53).

Contudo, foi justamente no programa para ciências da natureza que Freud se espelhou. Importou conceitos da mais dura das ciências, a física, utilizou a perspectiva dinâmica (que supõe movimento de forças atuantes no aparelho psíquico) para explicar os conflitos pulsionais que atuam sobre o individuo e, com isso, naturalizou o psiquismo e alocou a psicanálise na seara das ciências naturais.

Para Heidegger, os fenômenos humanos não devem ser interpretados a partir de uma terminologia fisicalista. É neste sentido que o filósofo nos fala que o conceito de pulsão padece de uma objetividade não-humana. As escolhas epistemológicas de Freud representam algo que, ao olhar de Heidegger, está a serviço da naturalização do existir e coloca o pai da psicanálise na condição de arauto das ciências da natureza. Concluímos esse artigo entendendo que tal posição, apesar de polêmica e veemente, encontra 
diferentes ressonâncias em abordagens de epistemólogos da psicanálise - Assoun, Fulgencio, Loparic, Safatle - e no próprio texto de Freud.

\section{NOTAS}

${ }^{1}$ Graduanda em Psicologia pela Universidade Federal da Bahia. E-mail: vaniabarbosa.js@gmail.com. Esse texto é fruto de uma pesquisa de iniciação científica financiada pela FAPESB no período 2014-2015.

${ }^{2}$ Professora Titular de Filosofia pela Universidade Estadual de Feira de Santana (UEFS). Doutora em Filosofia pela Universidade Estadual de Campinas (UNICAMP) E-mail: carolinevasconcelos@hotmail.com.

3 Estamos aqui falando da "querela dos métodos", a qual opõe metodologicamente os verbos explicar e compreender. Enquanto as ciências naturais almejam explicar os objetos mediante o estabelecimento de leis universais e juízos de realidade, as ciências do espírito ou humanas, em contrapartida, visam compreender os fenômenos a partir de sua singularidade situada historicamente, a partir de uma busca pelo sentido. Cf.: Assoun, 1983.

${ }^{4}$ Sobre o termo Daisen cumpre destacar que se trata de um vocábulo em que Heidegger procura dizer a Essência do homem pensada originariamente. Como nos lembra Leão o termo é formado de Sein (ser) e de $d a$ (aqui, lá, como advérbio, e o aqui, o lugar, como substantivo). Assim Dasein diz o aqui, o lugar do Ser, isto é, a dimensão instituída pelo ser onde este se manifesta. cf.: Leão, 2004. Heidegger, na obra Que é metafísica?, esclarece o porquê do uso do termo Dasein para tratar do homem em sua filosofia. O filósofo afirma: "Para reunir, ao mesmo tempo, numa palavra, tanto a relação do ser com a essência do homem, 
como também a referência fundamental do homem à abertura ('aí') do ser enquanto tal, foi escolhido para o âmbito essencial, em que se situa o homem enquanto homem, o nome 'ser-aí' [Dasein]" (HEIDEGGER,1991, p. 58). Por existir uma diversidade de traduções resolvemos manter o termo em alemão.

${ }^{5}$ Os conceitos da teoria metapsicológica são formulados por Freud segundo três pontos de vista: “(...) tópico (espacial), dinâmico (forças) e econômico (energia), que lhe servem de guia na elaboração de explicações em termos de conceitos relativos ao aparelho psíquico, a forças e a quantidades de energia" (LOPARIC, 2001, p.10).

${ }^{6}$ Apesar de se tratar de uma teoria que se serve de conceitos abstratos e de natureza convencional Heidegger entende que a metapsicologia de Freud está afinada aos procedimentos das ciências da natureza e que o conceito de pulsão padece de uma objetividade não-humana. Freud (1996a), por sua vez, indica que a sua teoria das pulsões é uma mitologia. Mais adiante confrontaremos estas duas posições.

${ }^{7}$ Loparic nos esclarece sobre o valor heurístico de alguns conceitos: “(...) eles são usados como guias da pesquisa empírica no domínio de objetos materiais sensíveis, ou seja, como princípio a priori da atividade de resolução de problemas, desenvolvida pela ciência empírica" (LOPARIC, 2003, p. 5).

${ }^{8}$ Não cabe ao escopo deste artigo detalhar a influência de neokantianos sobre a psicanálise de Freud. Mas, de modo sumário, convém indicar a influência do neokantiano Hans Vaihinger e de sua teoria do como se a qual autoriza o pesquisador a fazer comparações e analogias para descrever um objeto que não é passível de observação direta - na teorização do psiquismo humano como um aparelho. Freud não advoga a existência de uma máquina no homem, mas presume que seu psiquismo funcione como se fosse um aparato. Outra herança da qual Freud se serve concerne, segundo Loparic (2005, p.245), à metodologia convencionalista, também de origem kantiana e muito difundida entre 
os cientistas de língua alemã. Segundo tal metodologia, a ciência pode lançar mão de convenções teóricas que não encontram referentes empíricos, mas que são profícuas na organização de dados observáveis. ${ }^{9}$ Para Fulgencio “(...) a maneira como Freud opera teoricamente na formulação do conceito de pulsão tem não só uma proximidade com o lugar que Kant dá aos conceitos puros da razão, como também obedece ao mesmo tipo de necessidade metafísica que caracteriza as ciências naturais no programa de pesquisa kantiano" (FULGENCIO, 2003b, p. $16)$.

\section{REFERÊNCIAS BIBLIOGRÁFICAS}

ASSUON, Paul Laurent. Introdução à epistemologia freudiana. Rio de Janeiro: Imago, 1983.

CASANOVA, M. Compreender Heidegger. 2ed. Petrópolis, RJ: Vozes, 2010. (Série Compreender).

FREUD, S. "Ansiedade e vida pulsional". In: Edição Standard brasileira das obras completas de Sigmund Freud. Rio de Janeiro: Imago Editora, 1996a. Vol. XXII.

FREUD, S. “A pulsão e seus destinos”. In: Edição Standard brasileira das obras completas de Sigmund Freud. Rio de Janeiro: Imago Editora, 1996b. Vol. XIV. 
O CONCEITO DE PULSÃO NA PSICANALISE FREUDIANA...

FREUD, S. “Análise terminável e interminável”. in: Obras psicológicas completas de Sigmund Freud. Rio de Janeiro: Imago Editora, 1996c Vol. XXIII.

FREUD, S. "Esboço de psicanálise". In: Edição Standard brasileira das obras completas de Sigmund Freud. Rio de Janeiro: Imago Editora, 1996d. Vol. XXIII.

FREUD, S. “Algumas lições elementares de psicanálise”. in: Obras psicológicas completas de Sigmund Freud. Rio de Janeiro: Imago Editora, 1996e Vol. XXIII.

FREUD, S. "O inconsciente". In: Obras psicológicas completas de Sigmund Freud. Tradução de Luiz Alberto Hans. - Rio de Janeiro: Imago Editora. Vol. II, 2006a.

FREUD, S. "O Recalque”. In: Obras psicológicas completas de Sigmund Freud. Tradução de Luiz Alberto Hanns. - Rio de Janeiro: Imago Editora. Vol. II, 2006 b.

FULGENCIO, L. "As Especulações metapsicológicas de Freud". In: Natureza Humana - Revista Internacional de Filosofia e Psicanálise. São Paulo: EDUC, vol. 3 n. 1, 2003a.

FULGENCIO, L. "Kant e as especulações metapsicológicas em Freud". In: Kant e-Prints - Campinas, vol. 2, 2003b.

FULGENCIO, L. O método especulativo em Freud. São Paulo: EDUC, 2008.

GARCIA-ROZA, L. "Introdução à metapsicologia freudiana", v.3. Artigos de metapsicologia: narcisismo, pulsão, recalque, inconsciente. $7^{\mathrm{a}}$ ed. Rio de Janeiro: Jorge Zahar Ed., 1995. 
HANNS, Luiz Alberto. Dicionário comentado de alemão de Freud. Rio de Janeiro: Imago Ed., 1996.

HEIDEGGER, M. Seminários de Zollikon. Tradução de Gabriela Arnhold, Maria de Fátima de Almeida Prado. São Paulo: EDUC; Petrópolis, RJ: Vozes, 2001.

HEIDEGGER, M. Carta sobre o humanismo. Introdução, tradução e notas de Emmanuel Carneiro Leão. 3. ed. Rio de Janeiro: Edições Tempo Brasileiro, 2009.

HEIDEGGER, M. Ser e Tempo. Tradução e notas de Maria Sá Cavalcante Shuback. Petrópolis: Vozes, 2004.

HEIDEGGER, M. “O que é metafísica?” In: Conferências e escritos filosóficos. (Coleção os pensadores) Tradução e notas de Ernildo Stein. São Paulo. Abril Cultural, 1991.

INWOOD, M. Dicionário Heidegger. Tradução de Luísa Buarque de Holanda. Rio de Janeiro: Jorge Zahar Editor, 2002.

KANT, Immanuel. Princípios metafísicos da natureza. Tradução de Artur Morão. Rio de Janeiro: Edições 70, 1990.

LAPLANCHE, J. E PONTALIS, J.B. Vocabulário da Psicanálise. Tradução: Pedro Tamen. São Paulo: Martins Fontes, 2001.

LEÃO. E.C. "Prefácio". In: HEIDEGGER, M. Ser e Tempo. Tradução e notas de Marcia Sá Cavalcante Schuback. Petrópolis: Vozes, 2004. 
O CONCEITO DE PULSÃO NA PSICANALISE FREUDIANA...

LOPARIC, Z. “A máquina no Homem”. In: FULGENCIO, L. e SIMANKE, R. (org). Freud na Filosofia Brasileira. São Paulo: Escuta, 2005.

LOPARIC, Z. "Além do Inconsciente - sobre a desconstrução heideggeriana da psicanálise". In: Natureza Humana - Revista Internacional de Filosofia e Psicanálise. São Paulo: EDUC, vol. 3.n 1, 2001.

LOPARIC, Zeljko. "De Kant a Freud: um roteiro". In: Natureza humana - Revista Internacional de Filosofia e Psicanálise. São Paulo: EDUC, v. 5, n. 1, jan-jun. 2003.

SAFATLE, V. e MONZI, R. (org). A filosofia após Freud. São Paulo: Humanitas, 2008.

SAFRANSKI, R. Heidegger: um mestre da Alemanha entre o bem e o mal. São Paulo: Geração editorial, 2000. 